Natural and Applied Sciences International Journal (NASIJ) eISSN: 2788-4619 (online)

https://doi.org/10.47264/idea.nasij/2.1.4

Vol. 2, No. 1, (January-December 2021), 39-55

https://www.ideapublishers.org/index.php/nasij

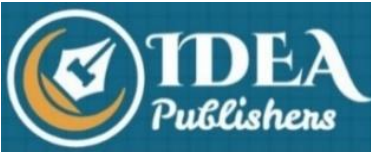

Research Article

\title{
Remote sensing evaluation of land surface temperature and urban area expansion in Zhengzhou city during 2013-2015
}

Sheheryar Khan ${ }^{1-2} \mid$ Sajid Gul ${ }^{3} \mid$ Weidong $\mathrm{Li}^{1-2}$

1. College of Information Engineering, Henan University of Technology, Zhengzhou, China.

2. Key Laboratory of Grain Information Processing and Control, Henan University of Technology, Zhengzhou, China.

3. School of Mathematics and Statistics, Zhengzhou University, Zhengzhou, China.

* Corresponding Author Email: 3sadmin@gmail.com

Published: November 26, 2021

\begin{abstract}
The Urban Heat Island (UHI) concept is one of the most serious ecological and social challenges of the urbanisation. As a result of these events, several man-made urban areas have displaced the rural areas with increased thermal conductivity surfaces, resulting in higher temperatures in the urban areas. Thus, this paper analyses the variations in Land Surface Temperature (LST) and the heat island area using Landsat 8 data and NPP VIIRS night-time light data. The data sources during 2013-2015 of Zhengzhou city, China, are selected to be a case study in this research work. According to the research, the economic centre of Zhengzhou city is shifting eastward, and the mean centre of urban area acquired from NPP VIIRS night-light data is extremely similar to the heat island area derived from Landsat 8 data. Also, the heat island areas obtained from the NPP VIIRS night-light data, and the yearbook data of Zhengzhou Bureau of Statistics are comparable with the accuracies of 96-99\%. Hence, our proposed procedure can be implemented practically to point out the urban areas, to identify the UHI areas with high accuracies in other regions and also can be used to indicate how large the UHI effects on the urban area with increased population and industries.
\end{abstract}

Keywords: Landsat 8, remote sensing, surface temperature, land surface temperature, monowindow algorithm, challenges of urbanisation.

How to Cite: Khan, S., Gul, S., \& Li, W. (2021). Remote sensing evaluation of land surface temperature and urban area expansion in Zhengzhou city during 2013-2015. Natural \& Applied Sciences International Journal (NASIJ), 2(1), 39-55. https://doi.org/10.47264/idea.nasij/2.1.4

Publisher's Note: IDEA PUBLISHERS (IDEA Publications Group) stands neutral regarding jurisdictional claims in the published maps and institutional affiliations.

Copyright: (C) 2021 The Author(s), published by IDEA PUBLISHERS (IDEA Publications Group)

Licensing: This is an Open Access article published under the Creative Commons AttributionNonCommercial 4.0 International License (http://creativecommons.org/licenses/by-nc/4.0/) 


\section{Introduction}

The Urban Heat Island (UHI) impact is a natural occurrence in man-made urban areas where rural landscapes have been covered by increased thermal conductivity and surface warmth (Soltani \& Sharifi, 2017). The temperature of the urban areas is higher than that of the rural areas, because the heat and the greenhouse gases surrounding the urban surfaces disrupt the energy balances between incoming and outgoing solar radiations (Mason et al., 2021). The UHI effect is thus like a heat island floating in a relatively cold ocean that is characterized as a human-stimulated climate and related to the distinctive features of urban and rural surfaces (Sturman \& Wanner, 2001). The use of heat-absorbing building materials (on streets, driveways, walkways, parking lots and rooftops) and the impervious surfaces with these materials reduce vegetation coverages (Yang et al., 2020). The artificial heat dissipation originated from cars, air conditioners, etc. are the main causes of UHI effect. Besides that, the magnitude of the UHI effect is reliant on the population, the size of the urban area, the topography, the location and the weather (Bhiwapurkar, 2007).

The consequences of UHI effect usually include the temporal and spatial variations of temperature and can also change the meteorological, geographical and urban characteristics (Yang et al., 2020). In general, cities have a heat island intensity (the difference between an urbanised and rural environment) of up to $10^{\circ} \mathrm{C}$. The rising temperature results in an unfavourable climate and increases the energy consumption due to more air conditioning requirements. Therefore, it is essential to incorporate the UHI effect in the future urban expansion (Chen et al., 2014). Numerous observational studies have been proposed to quantify the magnitude of the UHI effect and to monitor Land Surface Temperature (LST) using remotely sensed data in several urban and rural stations. New progress in the spatial, spectral, and temporal resolutions of remote sensing satellite data have opened up new possibilities for studying the effects and images of UHI regions (Imhoff et al., 2010; Ulivieri \& Cannizzaro, 1985; Watkins \& Thormodsgard, 1987).

LST values are one of the most important data for studying the heat island effect of urban area and for describing the exchange between surface energy and atmospheric energy, geological exploration, climate observation, environmental protection and agricultural production (Wang et al., 2019). It is the result of all interactions between the surface atmosphere and the energy mobility between the soil and the atmosphere therefore, it can be an excellent indicator of surface energy balance (Kaplan et al., 2018; Tsou et al., 2017). Many researchers have retrieved and investigated the LST values from remotely sensed data (Balçik, 2014; Guo et al., 2012; Sekertekin \& Bonafoni, 2020). Furthermore, several studies have presented the improved mono-window algorithms for calculating the LST values from remotely sensed data (Du et al., 2015; Käfer et al., 2020; Rongali et al., 2018; Wang et al., 2015).

To obtain the LST values over Zhengzhou city, China, we used a single channel algorithm (or mono-window algorithm) in conjunction with the surface emissivity and incoming solar radiation. The objectives of this study are to determine the UHI using Landsat 8 data and nighttime remote sensing data from the Suomi National Polar-orbiting Partnership: - NPP (NPP VIIRS), as well as to investigate the UHI boundaries and night-time urban area variations between 2013 and 2015. The rest of this article is arranged as follows. Section 2 describes the research area and the data that were analysed in this work. Section 3 discusses the research methods, while Section 4 considers the findings and discussion. At last, the Section 5 draws the conclusion. 


\section{Study area and data used}

A Global Navigation Satellite System (GNSS) network of Geographical Survey Institute (GSI) designated as GNSS Earth Observation Network (GEONET) is employed in this work to study the continental and oceanic Zhengzhou city, China is selected to study in this work, because it is the economic centre of Henan province with typical warm monsoon climate. Zhengzhou's industry has developed rapidly since 1992 . Hence, its population reached up to 9.51 million people within $7446.2 \mathrm{~km}^{2}$ (Mu et al., 2016).

Many human-made items have caused a significantly increased UBI effect in Zhengzhou. Two main data used in this work consist of the NPP VIIRS night-light data and the Landsat 8 data over Zhengzhou city during 2013-2015. To initiate, the average night-light data from NPP VIIRS are used to examine changes in urban areas. The National Geophysical Data Centre (NGDC) provides the NPP VIIRS night-light data. Although the NPP satellite was launched in April 2012, noise intrusion from sources other than flashlights has not been eliminated from the NPP VIIRS night-light data (Ma et al., 2014). The benefits of the NPP VIIRS sensor are a wide-angle reflection and a light oversaturating elimination, hence, it improves greatly the sharpness of satellite images (Zheng et al., 2019). When processing the data, the projection of the NPP VIIRS night-light data must be transformed into the area of the Albers projection. This study is dedicated to extract the general surroundings of Zhengzhou using NPP-VIIRS nighttime remote sensing data and to get the correlation of Zhengzhou UHI area.

The Landsat 8 data used in this research are the surface reflections and TIR radiation from the US Geological Survey (USGS). The Landsat 8 satellite is equipped with two sensors in this instance, the Operational Land Imager (OLI) and the Thermal Infrared Sensor (TIRS) (Keeratikasikorn \& Bonafoni, 2018). The OLI sensor features seven reflective bands (visible, near infrared and short-wave infrared), as well as two panchromatic and cirrus bands, while the TIRS sensor features two TIR bands. OLI and TIRS channels have spatial resolutions of $30 \mathrm{~m}$ and $100 \mathrm{~m}$, respectively. The TIRS data are delivered at a distance of $30 \mathrm{~m}$ following a cubic convolution resampling.

\section{Methods and material}

In this study, the Landsat 8 satellite images and NPP VIIRS night-time remote sensing data from the year 2013 to 2015 are used to determine the effects of UHI and to gain a deeper understanding of the built-up area's centres. Furthermore, the relationship between LST and the Normalised Difference Vegetation Index (NDVI) is decided using Landsat 8 red and the near-infrared band data. The LST distribution is derived using a mono-window approach from the Landsat 8 data, with bands 10 and 11 used to obtain Top-of-Atmosphere radiance (TOA) and satellite brightness temperature, respectively. Regarding that, the NPP VIIRS night-light information is analysed in conjunction with the Landsat 8 data to obtain data for the study area. The output centres of Zhengzhou's built-up area are compared to those obtained from NPP VIIRS night-light data using Landsat 8 data. The critical methods used in this article are continues to follow:

\subsection{Image pre-processing}

The data shows that each pixel in the original remote sensing data has a Digital Number (DN), which corresponds to the original size recorded by the sensor. To acquire computable data from 
these images, we need to convert the DNs into the physical quantities, brightness and brightness temperature. Next, we need to modify the previously calibrated image due to atmospheric influences. The presence of the atmosphere can cause significant distortion of radiation measurement signals. The Landsat 8 images are converted to the TOA radiant density $\left(L_{\lambda}\right)$ using (1).

$$
L_{\lambda}=\left(\frac{L_{M A X \lambda}-L_{M I N \lambda}}{Q c a l_{M A X}}\right) Q c a l+L_{M I N \lambda}
$$

Where Qcal is the quantitative calibration pixel value of $\mathrm{DN}, L_{M I N \lambda}$ and $L_{M A X \lambda}$ are the spectral emission brightness's cores-ponding to $\operatorname{Qcal}_{M I N}(\mathrm{DN}=0)$ and $\operatorname{Qcal}_{M A X}(\mathrm{DN}=255)$, respectively (Balaji \& Sumathi, 2014). Since the $L_{\lambda}$ does not consider the atmospheric effects, the images must be converted from the radiation into the reflectivity. In addition, the apparent reflection model, the image-based Dark Object Subtraction (DOS) and the radiation correction models are also used to correct the additional scattering component of the atmosphere due to the radiation brightness of the path. The conversion of the satellite radiation into the surface reflection and the compensation of the effects of solar radiation (solar radiation and solar zenith) and atmosphere are considered in the following equation (Moran et al., 1992; Sobrino et al., 2004).

$$
\rho_{\text {sup }}(\lambda)=\frac{\pi\left[L_{\text {sat }}(\lambda)-L_{p}(\lambda)\right] d^{2}}{\tau_{v}(\lambda) \cdot\left[E_{0}(\lambda) \cdot \cos \vartheta_{z} \cdot \tau_{z}(\lambda)\right]+E_{\mathrm{d} 0 \mathrm{mn}}(\lambda)}
$$

Where $L_{s a t}(\lambda)$ is the radiation from the satellite sensor, and $L_{p}(\lambda)$ is the path radiation generated by the interaction between the electromagnetic radiation and the atmospheric components (molecules and aerosols). The $\tau_{v}(\lambda)$ and $\tau_{z}(\lambda)$ are the air permeabilities along the path from the soil surface to the sensor, and vice versa. The $\vartheta_{0}$ is the zenith angle of the Sun, and the $d^{2}$ is the embedded secondary Earth-Sun distance term. Moreover, the $E_{0}(\lambda)$ is the spectral solar radiation that is perpendicular to the surface of the Sun's rays outside the atmosphere. Lastly, the $E_{\mathrm{d} 0 \mathrm{mn}}(\lambda)$ is the spectral emission of surface wells caused by the scattered flux in the atmosphere.

\subsection{Normalized Difference Vegetation Index (NDVI)}

The NDVI is a systematic index that provides us to analyse vegetable development and record the evolution of the land surface. This index is used to compare the properties of two bands in a multispectral data set, for example, the absorption of chlorophyll pigments in the red band and the high reflectivity of plant materials in the near-infrared (NIR) band (Giannico, 2007; Gupta et al., 1995). The NDVI is computed using the below equation.

$$
\mathrm{NDVI}=\frac{\mathrm{NIR}-\mathrm{RED}}{\mathrm{NIR}+\mathrm{RED}}
$$


In the above equation NIR and RED are the near-infrared and red bands' pixel values, respectively. Table-1 contains examples of both reflectance values (red and near-infrared channels) and computed NDVI values. The NDVI values are typically between -1.0 and 1.0. For instance, the very low NDVI values ( 0.1 or less) corresponds to the dry bare soil, cloud, snow and ice, as well as water. Meanwhile, the medium NDVI values (0.2-0.5) represent the shrubs and the grasslands, and the high NDVI values (0.6-1.0) represent the temperate and tropical rainforests.

Table-1: Reflectance values in RED and NIR channels along with the computed NDVI values

\begin{tabular}{|l|c|c|c|}
\hline Cover type & RED channel & NIR channel & NDVI value \\
\hline Dense vegetation & 0.10 & 0.50 & 0.70 \\
\hline Dry Bare soil & 0.2691 & 0.2831 & 0.0251 \\
\hline Clouds & 0.2276 & 0.2282 & 0.0020 \\
\hline Snow and ice & 0.3757 & 0.3425 & -0.0460 \\
\hline Water & 0.0224 & 0.0132 & -0.2571 \\
\hline
\end{tabular}

\subsection{Retrieval of Land Surface Temperature (LST)}

After NDVI calculation, the TOA brightness temperature $\left(\mathrm{T}_{\mathrm{B}}\right)$ of the satellite (unit: Kelvin or $\mathrm{K}$ ) is computed in this subsection by converting the spectral radiance in the hypothesis of uniform emissivity by the subsequent equation:

$$
\mathrm{T}_{\mathrm{B}}=\frac{K_{2}}{\ln \left(K_{1} / L_{\text {sat }}+1\right)}
$$

Where $L_{s a t}$ and $K_{1}$ is the spectrum emission and the calibration constant (unit: $\mathrm{W} / \mathrm{m}^{2}$. sr. $\mu \mathrm{m}$ ), respectively, as well as $K_{2}$ is the calibration constant (unit: $\mathrm{K}$ because surface radiation is regulated by several elements such as water content, structure, and roughness, the precise calculation of surface temperature is restricted to an accurate surface radiation.(Snyder, Wan, Zhang, \& Feng, 1998). Hence, the contribution of various components belonging to the pixel can be computed according to the ratio. The modified LST equation for spectral emissivity is showed below (Artis \& Carnahan, 1982).

$$
\mathrm{LST}=\frac{\mathrm{T}_{\mathrm{B}}}{1+\ln (\varepsilon)\left(\lambda \mathrm{T}_{\mathrm{B}} / \rho\right)}
$$

where $\lambda$ is the emitted radiance wavelength of $11.45 \mu \mathrm{m}, \rho=\mathrm{h}^{*} \mathrm{c} / \sigma\left(1.438^{*} 10^{-2} \mathrm{mK}\right)$ with $\sigma$ is the Boltzmann constant $\left(1.38^{*} 10^{-23} \mathrm{~J} / \mathrm{K}\right), \mathrm{h}$ is the Planck's constant $\left(6.626^{*} 10^{-34} \mathrm{Js}\right), \mathrm{c}$ is the light velocity $\left(3^{*} 10^{8} \mathrm{~m} / \mathrm{s}\right), \varepsilon$ is the surface emissivity, and $\mathrm{T}_{\mathrm{B}}$ is computed from (3). The LST image of Zhengzhou city retrieved from (4) is illustrated in Figure 2 where the plants and the soil are the main surface layers of ground components corresponding to the relationship between LST and NDVI. 
Figure 1: NDVI image of Zhengzhou City

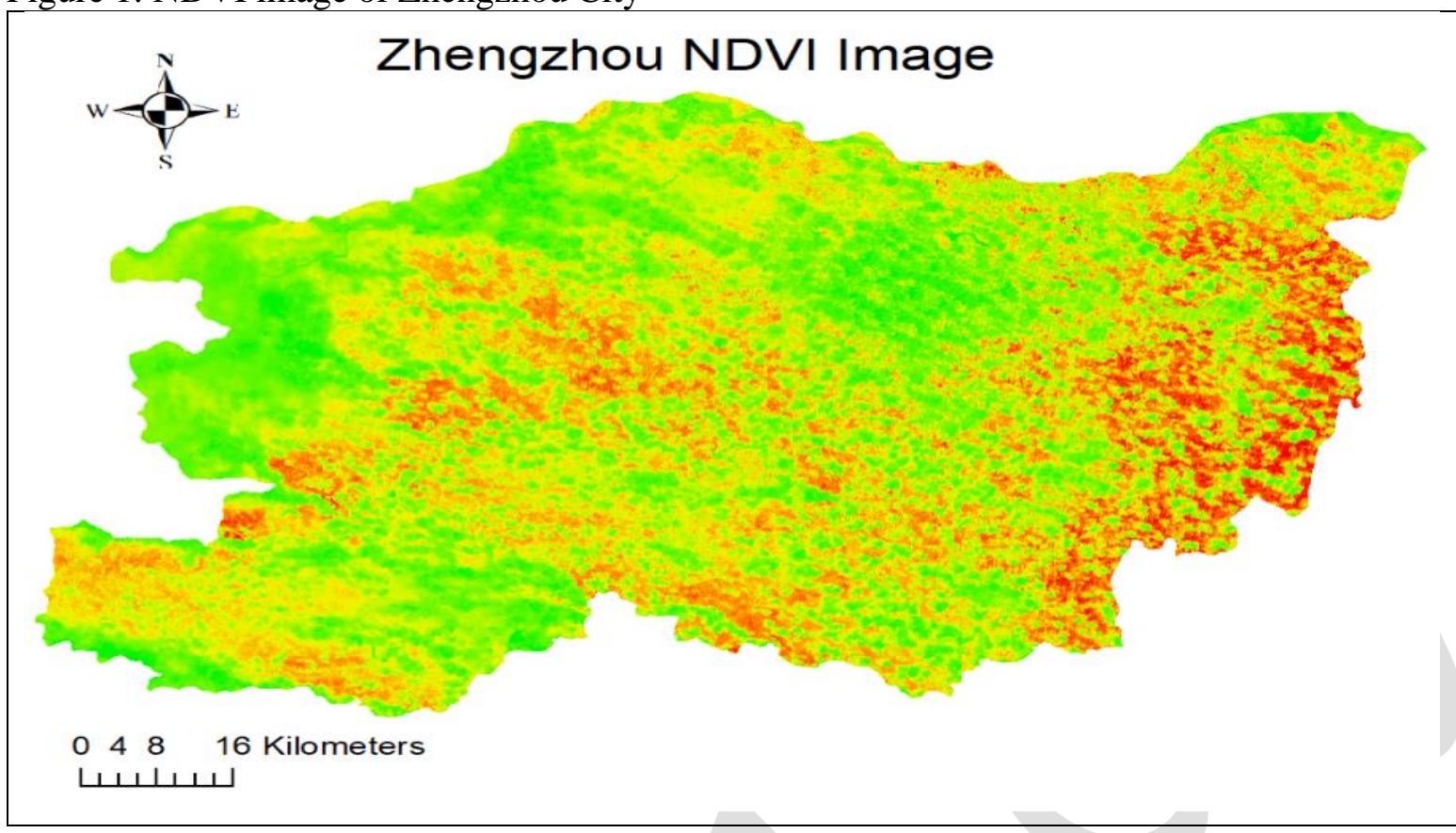

Figure 2: Retrieved Land Surface Temperature (LST) image of Zhengzhou City

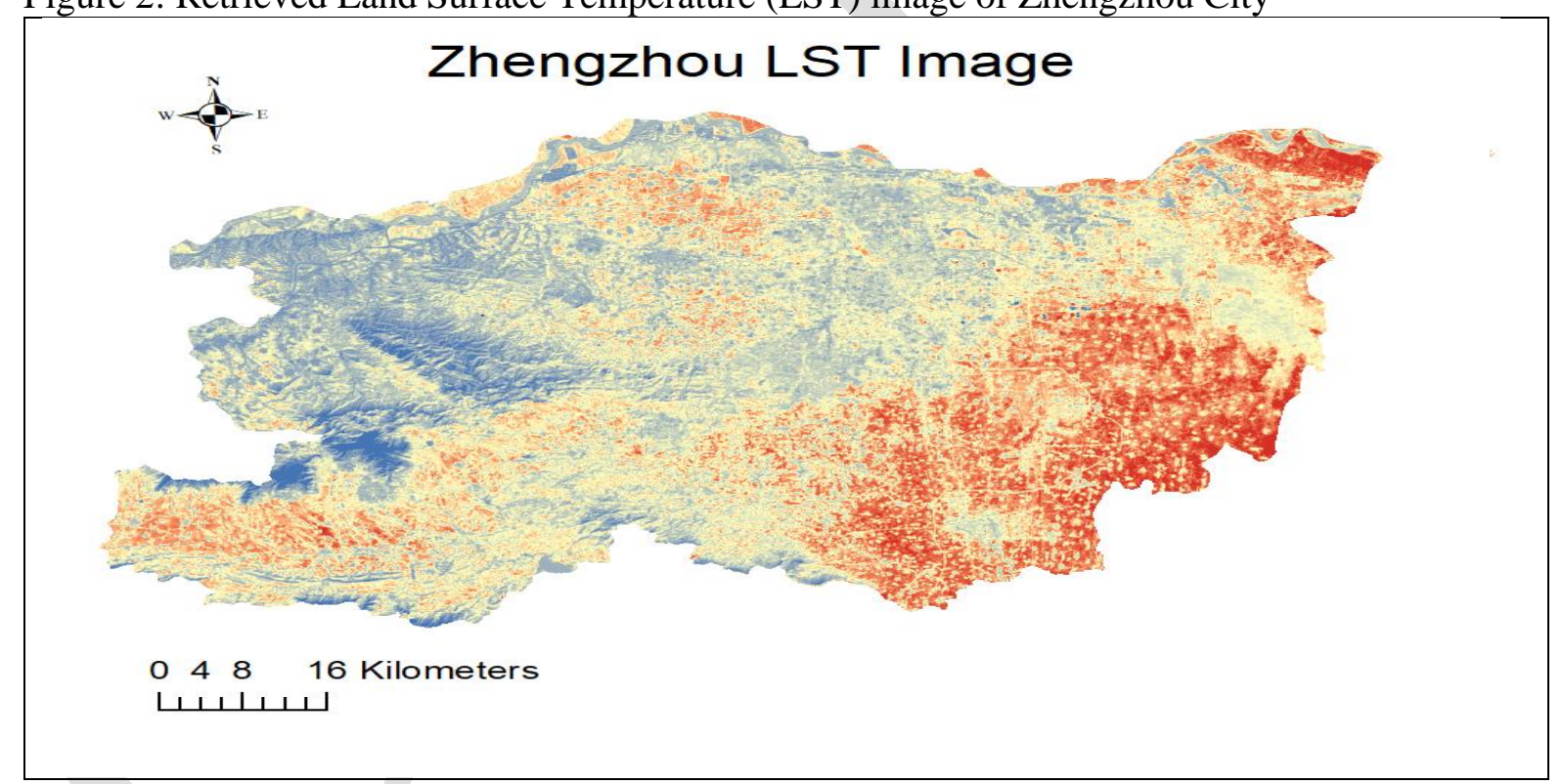

\subsection{Threshold technique}

The threshold technique is the most effective and simple non-context classification technique for grayscale or colour-based images. Using a single threshold, the grayscale or colour image will be converted to a binary image and displayed as a binary area map (Balaji \& Sumathi, 2014). Binary images are usually marked with two image areas, the previous image area and the next image area, which are zero (0) and non-zero (1) separated area, and the input data value of one image is lower than the threshold. Contains pixels, and another may contain pixels related to input values above the threshold. The classification depends on the image attributes for which the threshold is set and how the threshold is selected. In general, non-context 
thresholds may include more than one threshold and create three or more types of regions, so that the range of input image signals associated with each type of region is narrow and separated by some value.

When using LST data, only $80 \%$ of the temperature image data obtained by inversion is within the correct temperature range. Therefore, extract the area and get the centre point by using the threshold method exploiting 80\%-point data. The basic ideas are to use the idea of dichotomy in DMSP-OLS (Defence Meteorological Program Operational Line-Scan System) image, to set the threshold value of each administrative unit quickly, to extract the spatial pattern characteristics and area total information of urban land in each administrative unit, and to compare the area information in the extraction results with the urban land area of each administrative unit in the statistical data. Until a certain threshold condition, the total urban land area of each administrative unit extracted by DMSP-OLS is fully close to the statistical data. The proposed threshold setting consists mainly of the following steps:

(a). Set the potential town threshold of an administrative unit (Dt) and calculate the urban land area (Da) under this threshold as shown in (6) and (7).

$$
\begin{array}{r}
\text { Dt }=\operatorname{int}[(\text { Dmax }+ \text { Dmin }) / 2] \\
D a=\sum_{\text {Dmin }}^{\text {Dmax }} \mathrm{f}(\text { Dx })
\end{array}
$$

Where Dmax and Dmin are respectively the maximum and the minimum of DN values of light images in the administrative unit. Also, Dx represents a DN value of Dt-Dmax, and $\mathrm{f}(\mathrm{Dx})$ denotes the total area of urban land cells in the administrative unit with a DN value of Dx.

(b). Compare the difference $\mathrm{E}(\mathrm{Dt})$ between the Da value and the urban land area in the statistical data under the potential threshold of the administrative unit (S) and adjust the threshold range. Note that if $\mathrm{E}(\mathrm{Dt})<0$, then $\mathrm{Dmax}=\mathrm{Dt}$ and if $\mathrm{E}(\mathrm{Dt}) \geq 0$, then $\mathrm{Dmin}=\mathrm{Dt}$.

$$
\mathrm{E}(\mathrm{Dt})=\mathrm{Da}-\mathrm{S}
$$

(c). Reset the new threshold and repeat steps 1)-2) until the Da is close to the $\mathrm{S}$. Determine the threshold range in step 2), go to compute (5) and reset the new threshold, then calculate (6) and (7) for comparison, until the threshold (Dt) satisfies (8). The final Dt is the best urban land extraction threshold in Zhengzhou city that makes the total amount of urban land extracted fully close to the same period statistics.

$$
|\mathrm{E}(\mathrm{Dt}-1)| \geq|\mathrm{E}(\mathrm{Dt})| \leq|\mathrm{E}(\mathrm{Dt}+1)|
$$

Where $\mathrm{E}(\mathrm{Dt}), \mathrm{E}(\mathrm{Dt}-1), \mathrm{E}(\mathrm{Dt}+1)$ represent the Dt values at the current, the previous, and the next states.

\subsection{The centre of gravity and the transfer distance}

To evaluate the comprehensive development of Zhengzhou city, the calculation of the centre 
of gravity can be used to draw the generalization in physics. It means that the balance of power in all directions around a certain point in the regional space can be maintained. The economic and demographic statistics data are applied respectively to calculate the economic and population centre of gravity coordinates as shown in (9). Afterwards, the position of the centre of gravity of the study area is also computed using the pixel value as the research unit calculate as indicated in (10).

$$
X=\frac{\sum_{i=1}^{n} N i \times x i}{\sum_{i=1}^{n} N i} \quad, \quad Y=\frac{\sum_{i=1}^{n} N i \times y i}{\sum_{i=1}^{n} N i}
$$

where $(\mathrm{X}, \mathrm{Y})$ represents the centre of gravity coordinates of the region, $\left(\mathrm{x}_{\mathrm{i}}, \mathrm{y}_{\mathrm{i}}\right)$ denotes the coordinates of a second regional centre, and $\mathrm{N}_{\mathrm{i}}$ is the properties of the considered region such as GDP and the number of resident populations.

$$
X^{\prime}=\frac{\sum_{j=1}^{n} D N j \times x j}{\sum_{j=1}^{n} D N j}, \quad Y^{\prime}=\frac{\sum_{j=1}^{n} D N j \times y j}{\sum_{j=1}^{n} D N j}
$$

In (10), $\left(\mathrm{X}^{\prime}, \mathrm{Y}^{\prime}\right)$ represents the centre of gravity coordinates, $\mathrm{DN}_{\mathrm{j}}$ represents the grayscale value of the $\mathrm{j}^{\text {th }}$ cell, $\left(\mathrm{xj}_{\mathrm{j}}, \mathrm{y}_{\mathrm{j}}\right)$ denotes the pixel coordinates of the $\mathrm{j}^{\text {th }}$ image, and $\mathrm{n}$ signifies the absolute number of cells in the transverse longitudinal coordinates of the element.

Moreover, the regional centre of gravity can also be used to reflect the shift distance and angle of the centre of gravity. After getting the centre of gravity position in different years, the shift distance and angle are used to describe the shifts of the centre of gravity. Here, the transfer distance (Dtr) denotes the transfer distance of the centre of gravity over a certain period and can be computed using (11). Also, the $\theta$ tr represents the shift angle of the centre of gravity and is able to be calculated using (12).

$$
\begin{gathered}
\operatorname{Dtr}=\sqrt{(\mathrm{xt} 1-\mathrm{xt} 2)^{2}+(\mathrm{yt} 1-\mathrm{yt} 2)^{2}} \\
\theta \operatorname{tr}=\arctan [(\mathrm{yt} 1-\mathrm{yt} 2) /(\mathrm{xt} 1-\mathrm{xt} 2)]
\end{gathered}
$$

In (11) and (12), the Dtr is the movement distance of the gravity centre (unit: $\mathrm{km}$ ), as well as $\left(\mathrm{x}_{\mathrm{t} 1}, \mathrm{y}_{\mathrm{t} 1}\right)$ and $\left(\mathrm{x}_{\mathrm{t} 2}, \mathrm{y}_{\mathrm{t} 2}\right)$ are the centre of gravity coordinate during the considered years $\mathrm{t} 1$ and $\mathrm{t} 2$, respectively.

\section{Results and discussion}

\subsection{Change and expansion in the UHI area}

In this paper, the Landsat 8 data radiometric calibration is used to obtain the surface emissivity data, then the mono-window algorithm is used to retrieve the LST data. According to the observed statistics, the $20 \%$ value of the LST data obtained by the inversion is significantly higher than the others. Hence, the temperature values from high to low $20 \%$ of the LST data 
are selected as the threshold values of the UHI region. By using the ArcGIS (Aeronautical Reconnaissance Coverage Geographic Information System) contour function, the large-scale discrete heat island regions are obtained. Because the regional structure of Zhengzhou tends to multicore model in which the heat island region is more concentrated, so it belongs to the same area to draw the Heat Island of Zhengzhou city, which is easy to observe and analyse.

In Figure 3, the highlighted area in green, purple, and blue colours represent the heat island areas of Zhengzhou city for the years 2013,2014, and 2015, respectively. These built-up areas were extracted using Landsat8 data. The irregular NDVI and LST patterns for Zhengzhou city are likely an outcome of enlarged vegetation and suppressed heat fluidity in less condensed 25\%-50\% urban and suburban peripheral areas due to the supply (water) increase in these areas. The urban areas are subjugated by shorter low biomass vegetation, for instance, grassland, shrub lands, and savannah in Zhengzhou city. According to the Zhengzhou Bureau of Statistics data, the urban area during 2013-2015 are $365.61 \mathrm{~km}^{2}, 392.80 \mathrm{~km}^{2}$, and $410.00 \mathrm{~km}^{2}$, respectively as shown in Table-2. In Table-2, the urban area (unit: $\mathrm{km}^{2}$ ), the UHI area (unit: $\mathrm{km}^{2}$ ), and the ratio of UHI area and urban area (unit: \%) in each year are also shown in order to confirm the UHI expansion. The latter increases significantly from $50.57 \%$ in year 2013 to $64.70 \%$ in year 2015 . The rural regions surrounding the urban core are thinly vegetated and reinstate an imperative share of the captivated solar energy as rational heating. This study shows that the increase outward in the heat island area is quite immense in Zhengzhou city over the years.

Figure 3: The heat island areas portrayed by using the Landsat 8 satellite data in (a) year 2013, (b) year 2014 and (c) year 2015 of Zhengzhou city

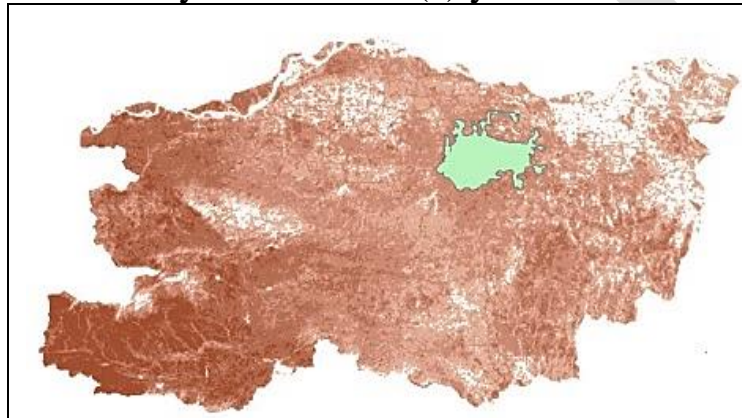

(a)

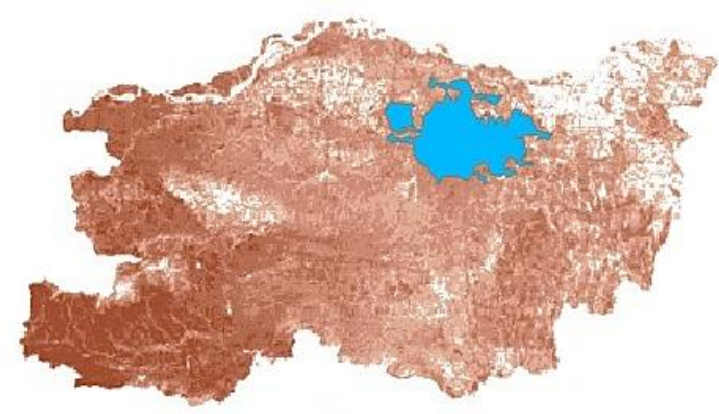

(c)

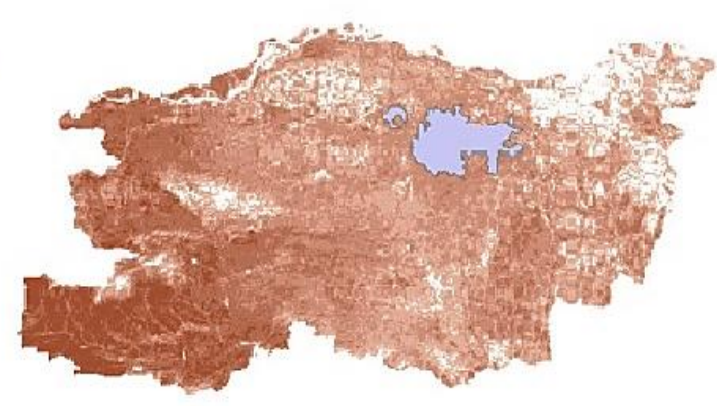

(b)
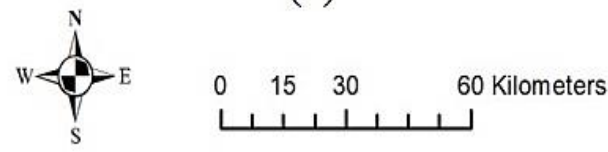

2013 Heat Island Area

2014 Heat Island Area

2015 Heat Island Area

Theoretically, the Landsat 8 remote sensing data from spatial analysis based on geographic information system is used to identify each urban area. It calibrates the layer internally according to the surface temperature density and estimate its size. By using the thresholds, we 
define different polygons in the Landsat8-based data. The boundary deter-mines a reasonable extent between the low-intensity urban area and the residential area, thereby providing a spatially reasonable urban agglomeration. Hence, the exact correspondence guarantees that the temperature contrasts inside the city polygons are founded on the acquisitions with the same parameter set. The central part of Zhengzhou is obviously changing, especially, the Xinxiang airport have been developing rapidly since 2014. Overall, the proposed method can be used to confirm that Zhengzhou city has been expanded continuously regarding the sizes of heat island areas during 2013-2015 as shown in Figure 3 and Table-2.

Table-2: The urban area and the UHI area (square kilometres) along with its ratio during 20132015 based on the LandSat 8 data

\begin{tabular}{|c|c|c|c|}
\hline Year & Urban area $\left(\mathrm{km}^{2}\right)$ & UHI area $\left(\mathrm{km}^{2}\right)$ & UHI area/Urban area \\
\hline 2013 & 365.61 & 184.89 & $50.57 \%$ \\
\hline 2014 & 392.80 & 207.14 & $52.73 \%$ \\
\hline 2015 & 410.00 & 265.25 & $64.70 \%$ \\
\hline
\end{tabular}

Moreover, the UHI region is used to calculate the monthly UHI at the centres of build-up (or urban) areas during 2013-2015 by using the centre of gravity where the small, shaded circles represent the centres of build-up areas for 12 months (No. 1-12) in the years 2013, 2014, and 2015. As seen in Figure 4, the centres of built-up areas are shifting from east to west in the winter as well as from east to southwest in the summer. The commercial research reports that the economic centre of Zhengzhou is steadily moving to the eastward. During the winter, the weather of Zhengzhou city is always quite foggy and hazy, and the centres of monthly buildup area are dispersed all over. In contrast, the centres of built-up areas are mostly close to one another in the summer for all studied three years.

Figure 4: The centres of build-up areas for 12 months (No. 1-12) in (a) year 2013, (b) year 2014, and (c) year 2015 of Zhengzhou city

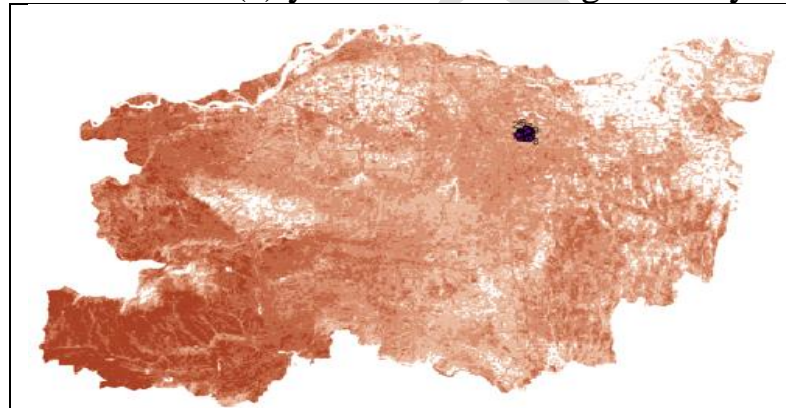

(a)

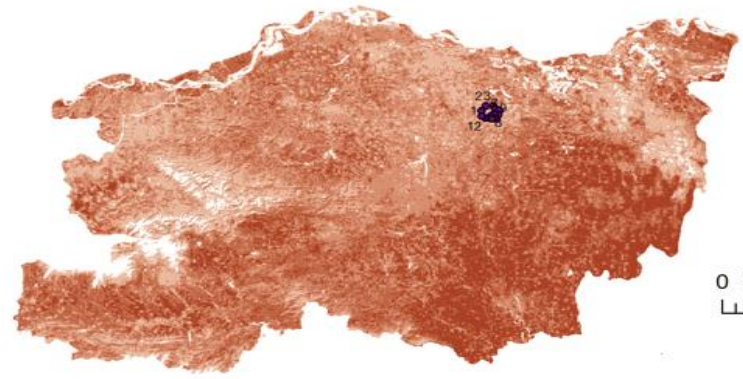

(c)

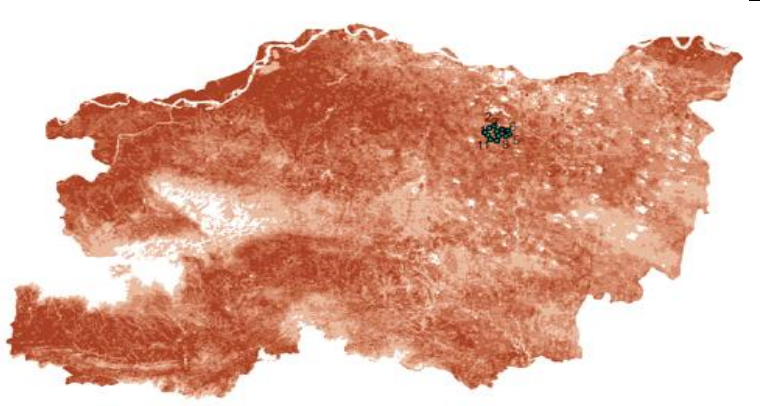

(b)

Legend

Centers of the build-up area for 12 months [No. 1-12] 
To judge the changing trend of heat island and the populated economic zone more clearly, the mean centres of built-up area are also considered using the mean centre tool function. Figure 5 shows the mean centres of built-up areas in the years 2013, 2014, and 2015 with yellow, blue, and green shaded circles, respectively, of Zhengzhou. As illustrated in Figure 5, the mean centres of built-up area in 2013 and 2014 are located at the nearby longitude while the mean centre in 2015 has been moved to the eastward of the Zhengzhou as shown in Table-3. This result is a good agreement with the gradual development of Zhengdong New District and it confirms that the human activities occur frequently at the mean centres of built-up area which also lead to the increases in the surface temperature.

Figure 5: The mean centres of built-up areas during 2013-2015 with yellow, blue, and green shaded circles, respectively, of Zhengzhou city

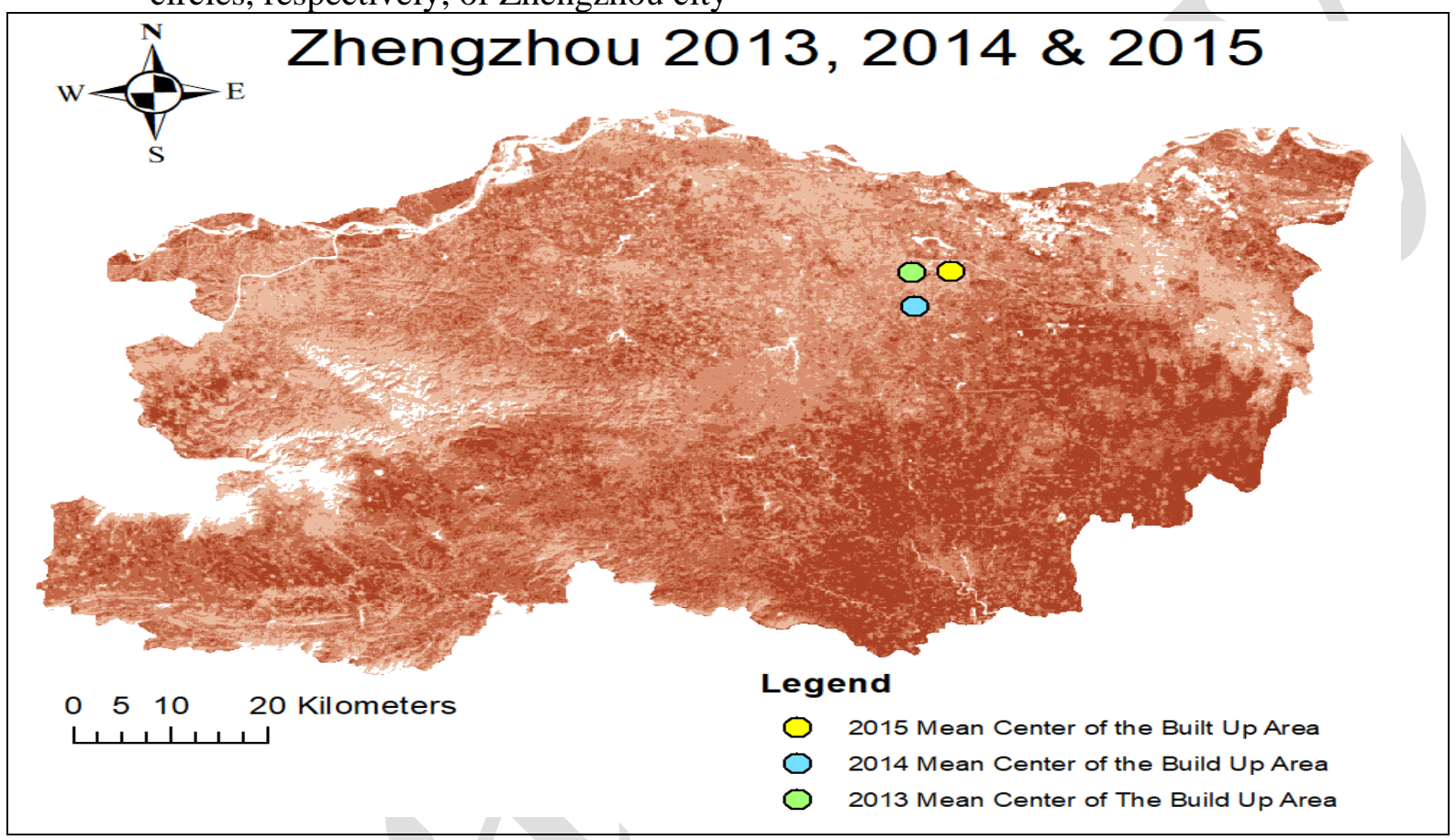

Table-3: The geographic locations of the mean centres of built-up area during 2013-2015

\begin{tabular}{|c|c|c|}
\hline \multirow{2}{*}{ Year } & Geographic Location of the mean centre \\
\cline { 2 - 3 } & longitude & latitude \\
\hline 2013 & $113^{\circ} 41^{\prime} 42.522^{\prime \prime} \mathrm{E}$ & $34^{\circ} 46^{\prime} 51.721^{\prime \prime} \mathrm{N}$ \\
\hline 2014 & $113^{\circ} 41^{\prime} 56.682^{\prime \prime} \mathrm{E}$ & $34^{\circ} 45^{\prime} 47.530^{\prime \prime} \mathrm{N}$ \\
\hline 2015 & $113^{\circ} 42^{\prime} 9.897^{\prime \prime} \mathrm{E}$ & $34^{\circ} 46^{\prime} 44.169^{\prime \prime} \mathrm{N}$ \\
\hline
\end{tabular}

\subsection{The changes in urban area with NPP VIIRS data}

In this study, the changes in urban area during night-time period are also analysed using NPP VIIRS night-light data. Firstly, the NPP VIIRS night-light data are initialized to get the study area data, then the night-light threshold value is calculated regarding to the yearbook of government statistics. Afterwards, the Aeronautical Reconnaissance Coverage Geographic Information System (ArcGIS) is employed to compute regionally both the centroids and the centroid areas of the urban settlement area during 2013-2015 in Zhengzhou city. 
Figure 6 illustrates the changes of urban areas during night-time period in the years 2013, 2014, and 2015 with orange, magenta, and green coloured areas, respectively, of Zhengzhou city. After the urban areas are calculated using NPP VIIRS night-light data, the computed heat island areas are equal to $372.66 \mathrm{~km}^{2}, 377.35 \mathrm{~km}^{2}$, and $412.73 \mathrm{~km}^{2}$ in the years 2013,2014 , and 2015 , respectively. These computed areas are very close to the observed areas from the yearbook data of Zhengzhou Bureau of Statistics with the accuracies of $96 \%-99 \%$ as seen in Table-4. It's obvious that the urban areas using the NPP VIIRS night-light in Figure 6 correspond well to the heat island areas using the Landsat 8 data in Figure 3. The heat island area in Zhengzhou city is growing to eastward direction (Zhengzhou New District) according to the three years of the research study of Zhengzhou city. In years 2013 and 2015, the heat island areas are larger significantly than the surveyed urban areas by Zhengzhou municipal government, which is quite alarming and massive. Although the comparisons in Table- 4 show relatively similar, but the NPP VIIRS sensors use a wide-angle radiation, so they can provide the night-light data more accurate. With the use of NPP VIIRS night-light data and the suggested approach, the urban regions may be provided with high accuracies and practical importance.

Figure 6: The changes of urban areas during night-time period in (a) year 2013, (b) year 2014, and (c) year 2015 of Zhengzhou city

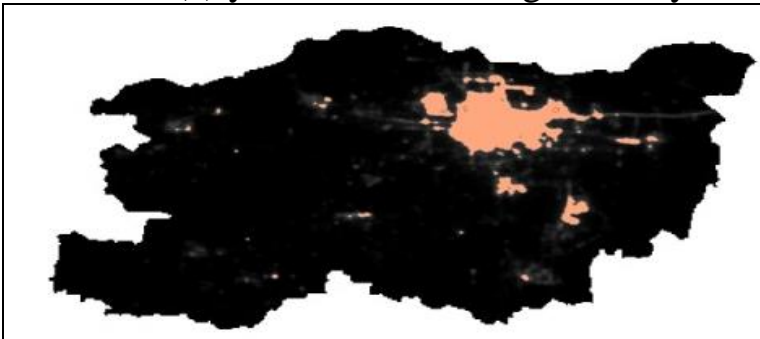

(a)

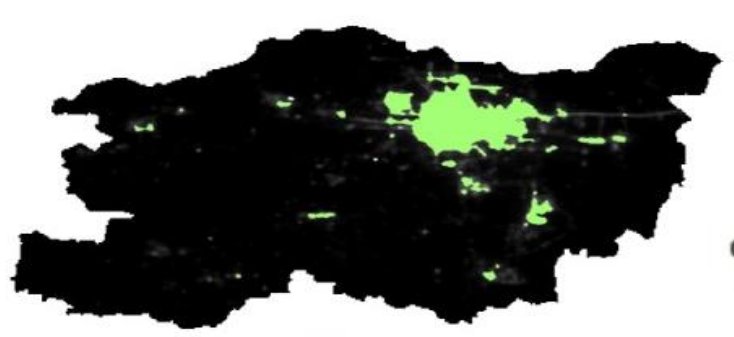

(c)

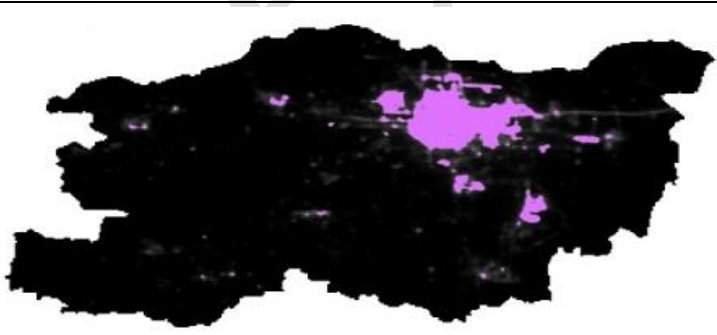

(b)

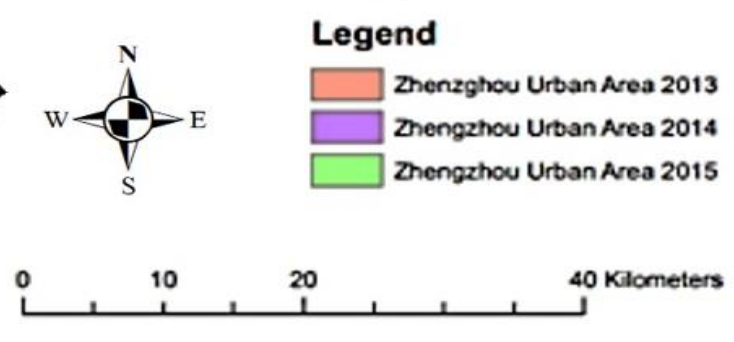

Table-4: The comparisons between the NPP VIIRS-based urban area and the yearbook data during 2013-2015

\begin{tabular}{|c|c|c|c|}
\hline Year & $\begin{array}{c}\text { NPP VIIRS-based urban area } \\
\left(\mathrm{km}^{2}\right)\end{array}$ & $\begin{array}{c}\text { Yearbook data } \\
\left(\mathrm{km}^{2}\right)\end{array}$ & $\begin{array}{c}\text { Accuracy } \\
(\%)\end{array}$ \\
\hline 2013 & 372.66 & 365.61 & 98 \\
\hline 2014 & 377.35 & 392.80 & 96 \\
\hline 2015 & 412.73 & 410.00 & 99 \\
\hline
\end{tabular}

\subsection{The relationship between heat island area and urban area}

The urban area expansion is analysed additionally by considering the relationship between the Landsat 8 data-based heat island areas (Table-2) and the NPP VIIRS data-based urban areas 
(Table-4) in term of a quadratic function. Figure 7 shows a quadratic equation of those areas during 2013-2015 of Zhengzhou city. The $\mathrm{x}$-axis and y-axis labels represent the NPP VIIRS data-based urban areas and the Landsat 8 data-based heat island areas, respectively. The correlation coefficient $\left(\mathrm{R}^{2}\right)$ being the degree of the fitting is equal to 0.9792 that reflects the excellent correlation concerning the urban built-up area and the UHI area. Consequently, the Zhengzhou Municipal Government reports that the urban built-up area in 2016 is equal to 443.0 $\mathrm{km}^{2}$, hence, the UHI area can be obtained about $324.10 \mathrm{~km}^{2}$. Table-5 shows the centre locations of urban built-up area based on NPP VIIRS night-light data during 2013-2015 of Zhengzhou city, China.

Figure 7: The relationship between heat island area and urban area in form of a quadratic function with high correlation coefficient of (0.9792).

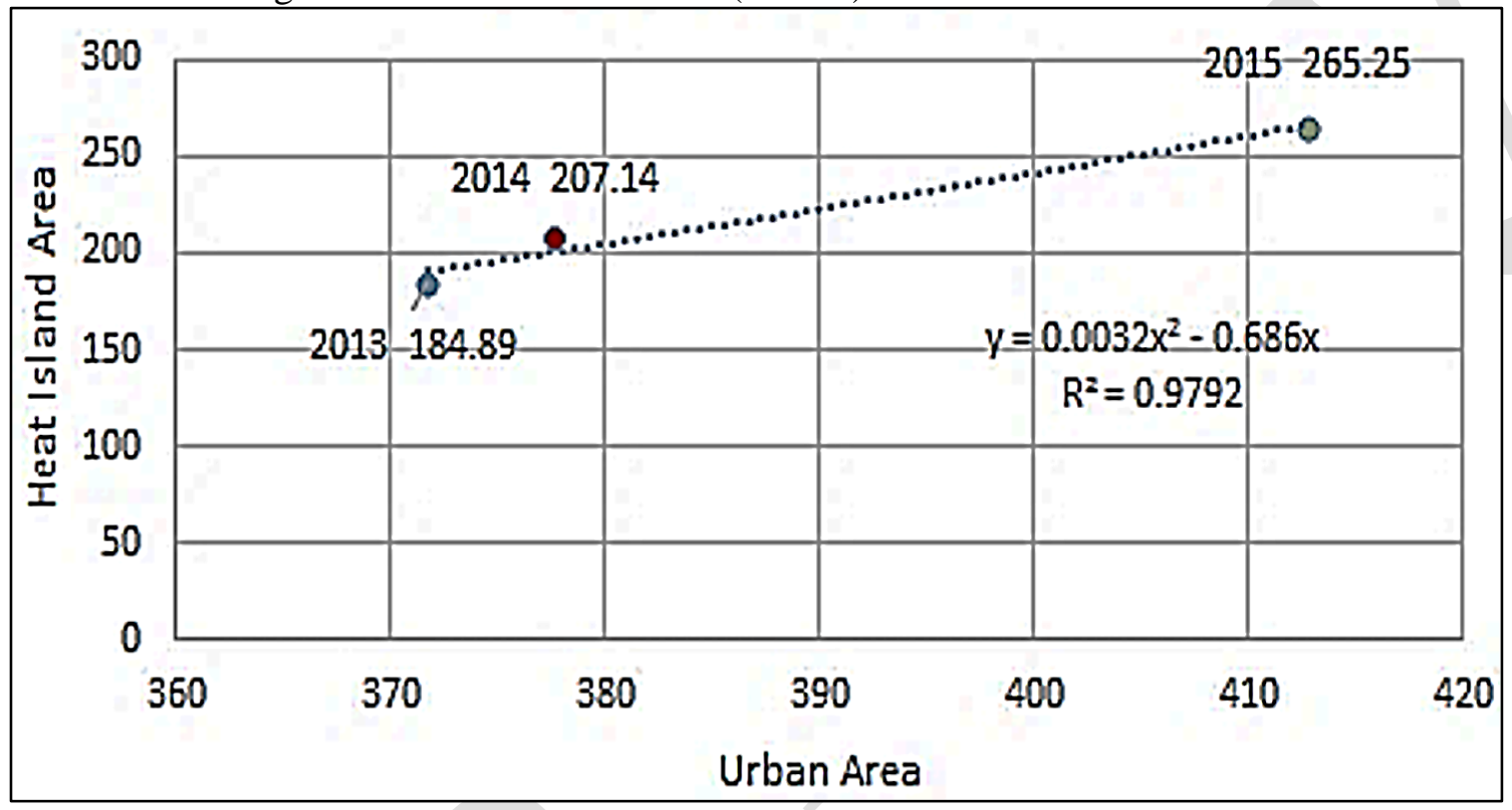

Table-5: The geographic locations of the centres of built-up area using NPP VIIRS night-light data during 2013-2015

\begin{tabular}{|c|c|c|}
\hline \multirow{2}{*}{ Year } & \multicolumn{2}{|c|}{ Geographic location of the centres of built-up area } \\
\cline { 2 - 3 } & Longitude & Latitude \\
\hline 2013 & $113^{\circ} 39^{\prime} 8.96 " \mathrm{E}$ & $34^{\circ} 41^{\prime} 52.729^{\prime \prime} \mathrm{N}$ \\
\hline 2014 & $113^{\circ} 41^{\prime} 18.83^{\prime \prime} \mathrm{E}$ & $34^{\circ} 43^{\prime} 0.261^{\prime \prime} \mathrm{N}$ \\
\hline 2015 & $113^{\circ} 39^{\prime} 19.35^{\prime \prime} \mathrm{E}$ & $34^{\circ} 42^{\prime} 55.066^{\prime \prime} \mathrm{N}$ \\
\hline
\end{tabular}

Subsequently, both the threshold dichotomy and the contour extraction are also utilized to determine the mean centres of heat island area and urban built-up area at Zhengzhou city through 2013-2015. The mean centre of heat island area assimilated from the Landsat 8 data is showed in Fig. 8(a), while that of urban built-up area acquired from the NPP VIIRS night-light data is showed in Fig. 8(b). Also, Table-6 reports the geographic locations of the mean centres of heat island area and urban built-up area. As seen in Fig. 8, the mean centres obtained from these two approaches are comparable that points to the same location of Zhengdong New District and shows the accurate results. This result confirms that the centres of the urban builtup area also point out those of UHI areas with high LST values. 
Figure 8: The comparison of the mean centres obtained from (a) Landsat 8 data and (b) NPP VIIRS night-light data during 2013-2015 of Zhengzhou city

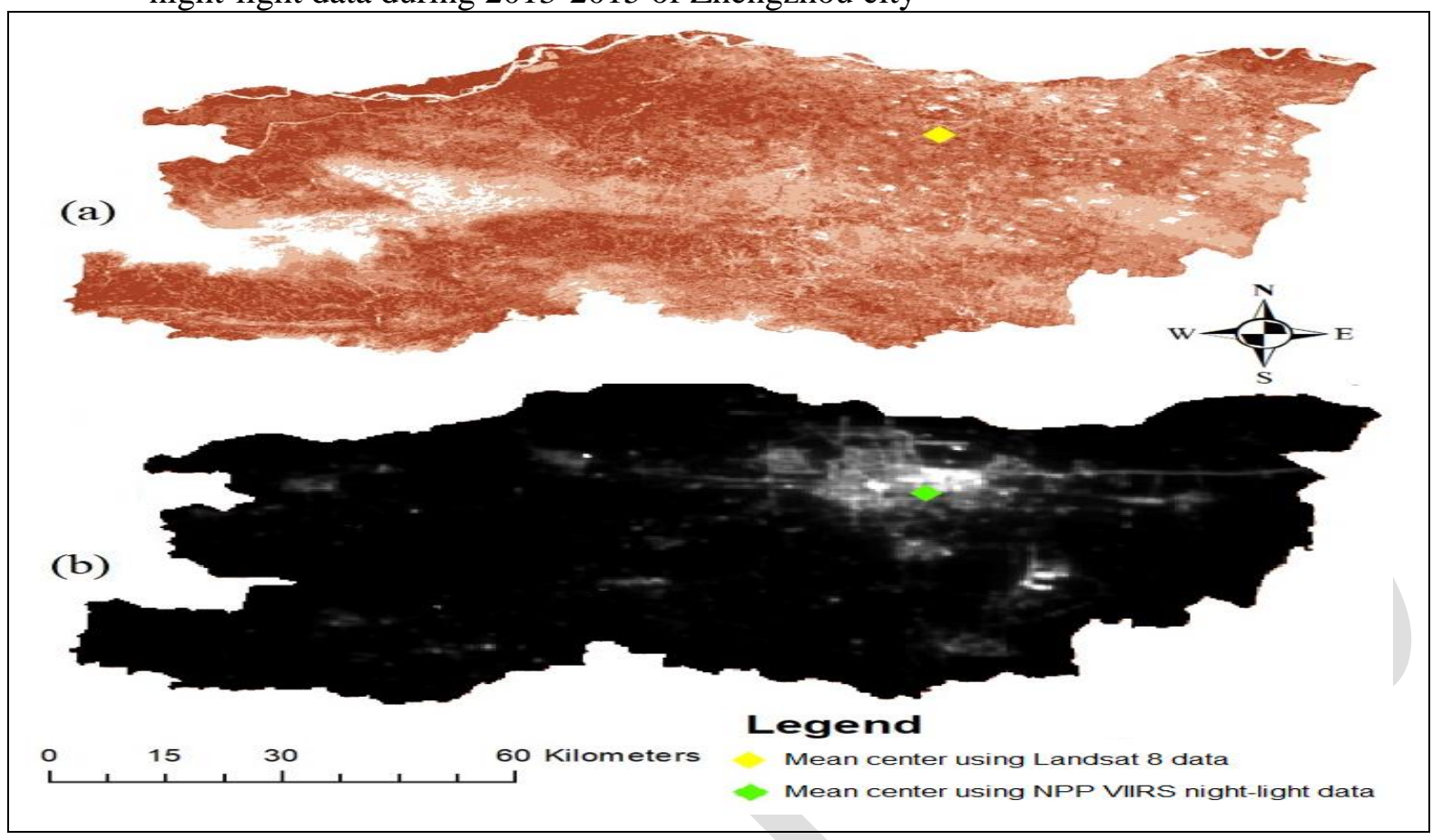

Table-6: The geographic locations of the mean centres of UHI area and urban built-up area during 2013-2015

\begin{tabular}{|c|c|c|}
\hline \multirow{2}{*}{ Data Type } & \multicolumn{2}{|c|}{ Geographic location } \\
\cline { 2 - 3 } & longitude & latitude \\
\hline $\begin{array}{c}\text { Urban Heat Island area } \\
\text { (Landsat 8 data) }\end{array}$ & $113^{\circ} 41^{\prime} 56.682^{\prime \prime} \mathrm{E}$ & $34^{\circ} 46^{\prime} 17.737^{\prime \prime} \mathrm{N}$ \\
\hline $\begin{array}{c}\text { Urban area } \\
\text { (NPP VIIRS data) }\end{array}$ & $113^{\circ} 42^{\prime} 7.481^{\prime \prime} \mathrm{E}$ & $34^{\circ} 43^{\prime} 29.418^{\prime \prime} \mathrm{N}$ \\
\hline
\end{tabular}

\section{Conclusions}

Variations in LST and UHI are investigated in this article using Landsat 8 satellite images and NPP VIIRS night-time light data during 2013-2015 in Zhengzhou city. While using LST data, only $80 \%$ of the temperature image data obtained by inversion is within the correct temperature range. Therefore, we can extract the areas and get the centre points by using threshold method with $80 \%$-point data. The normalised difference index is computed using the correlation between the LST values and the Landsat 8 red band 4 and near-infrared band 5 data (NDVI). The LST variance is extracted using the mono-window algorithm using Landsat 8 data bands 10 and 11. The heat island areas obtained from NPP VIIRS night-light data increase from $372.66 \mathrm{~km}^{2}$ in 2013 to $412.73 \mathrm{~km}^{2}$ in 2015 corresponding to the yearbook data of Zhengzhou Bureau of Statistics with the accuracies of $96 \%-99 \%$. Here, the economic centre of Zhengzhou city is moving to eastward, Zhengdong New District (one of the most populated regions in Zhengzhou city), corresponding to the research study of Zhengzhou city. Also, the UHI areas increase significantly from $184.89 \mathrm{~km}^{2}$ to $265.25 \mathrm{~km}^{2}$ from 2013 to 2015 . Hence, it confirms that the human activities occur frequently at the mean centres of built-up area which also lead to the increases in the surface temperature. 
The centres of the built-up area are shifting from west to east in the winter and from west to southwest in the summer. The centres of urban area are dispersed all over in the winter, while the centres of built-up area are close to one another in the summer. The heat island centre shift has a certain degree of lag relative to the city's centre of gravity shift. The mean centre of urban areas using NPP VIIRS night-light corresponds well to that of heat island area using Landsat 8 data.

\section{Declarations}

\section{Availability of data and materials}

The analysis in this paper employed the comprehensive meteorological information, the Landsat 8 data, and the NPP VIIRS night-time light data provided by the Zhengzhou bureau of Statistics, and the United States Geological Survey (USGS), and the National Oceanic and Atmospheric Administration (NOAA).

\section{Competing interests}

Not applicable.

\section{Funding}

Not applicable.

\section{Authors' Contributions}

SG and WL designed the idea and framework. SK did the analysis and paper write up. SK and SG contributed to the discussion and approved the final manuscript.

\section{Acknowledgements}

The authors are highly appreciated to the Henan University of technology, Zhengzhou for both the laboratories and the facilities that are available to make this research.

\section{Ethics approval and consent to participate}

Not applicable.

\section{Consent for publication}

Not applicable.

\section{Competing interests}

The authors declare that they have no competing interests. 


\section{References}

Artis, D. A., \& Carnahan, W. H. (1982). Survey of emissivity variability in thermography of urban areas. Remote Sensing of Environment, 12(4), 313-329. https://doi.org/10.1016/0034-4257(82)90043-8

Balaji, T., \& Sumathi, D. M. (2014). Effective features of remote sensing image classification using interactive adaptive thresholding method. arXiv preprint arXiv:1401.7743. https://arxiv.org/abs/1401.7743

Balçik, F. B. (2014). Determining the impact of urban components on land surface temperature of Istanbul by using remote sensing indices. Environmental Monitoring and Assessment, 186(2), 859-872. https://doi.org/10.1007/s10661-013-3427-5

Bhiwapurkar, P. (2007). Urban heat island phenomenon, urban morphology and building energy: The case of Chicago. Ph.D. Thesis, Graduate College of the Illinois Institute of Technology. https://www.proquest.com/docview/304860327

Chen, F., Yang, X., \& Zhu, W. (2014). WRF simulations of urban heat island under hotweather synoptic conditions: The case study of Hangzhou City, China. Atmospheric Research, 138, 364-377. https://doi.org/10.1016/j.atmosres.2013.12.005

Du, C., Ren, H., Qin, Q., Meng, J., \& Zhao, S. (2015). A practical split-window algorithm for estimating land surface temperature from Landsat 8 data. Remote Sensing, 7(1), 647665. https://doi.org/10.3390/rs70100647

Giannico, C. (2007). Remote sensing of vegetation in the calabrian region. Acta Astronautica, 60(2), 119-131. https://doi.org/10.1016/j.actaastro.2006.07.003

Guo, Z., Wang, S., Cheng, M., \& Shu, Y. (2012). Assess the effect of different degrees of urbanization on land surface temperature using remote sensing images. Procedia Environmental Sciences, 13, 935-942. https://doi.org/10.1016/j.proenv.2012.01.087

Gupta, R., Viswanadham, T., Prasad, S., \& Singh, B. (1995). Interrelationships between 0930, 1030, 1330 and $1430 \mathrm{~h}$ LANDSAT/TM and IRS/LISS spectral bands NDVI over the wheat growth cycle. Acta Astronautica, 35(7), 471-476. https://doi.org/10.1016/0094-5765(94)00282-Q

Imhoff, M. L., Zhang, P., Wolfe, R. E., \& Bounoua, L. (2010). Remote sensing of the urban heat island effect across biomes in the continental USA. Remote Sensing of environment, 114(3), 504-513. https://doi.org/10.1016/j.rse.2009.10.008

Käfer, P. S., Rolim, S. B., Heinz, L. V., Iglesias, M. L., da Rocha, N. S., \& Diaz, L. R. (2020). Assessment of single-channel algorithms for land surface temperature retrieval at two southern Brazil sites. Journal of Applied Remote Sensing, 14(1), 016507.

Kaplan, G., Avdan, U., \& Avdan, Z. Y. (2018). Urban heat island analysis using the landsat 8 satellite data: A case study in Skopje, Macedonia. In Multidisciplinary Digital Publishing Institute Proceedings, 2(7), 358).https://doi.org/10.3390/ecrs-2-05171

Keeratikasikorn, C., \& Bonafoni, S. (2018). Urban heat island analysis over the land use zoning plan of Bangkok by means of Landsat 8 imagery. Remote Sensing, 10(3), 440. https://doi.org/10.3390/rs10030440

Ma, T., Zhou, C., Pei, T., Haynie, S., \& Fan, J. (2014). Responses of Suomi-NPP VIIRSderived nighttime lights to socioeconomic activity in China's cities. Remote Sensing Letters, 5(2), 165-174. https://doi.org/10.1080/2150704X.2014.890758

Mason, J., Meixner, T., Rumpel, C., Lata, J. C., \& Galbraith, J. M. (2021). 24. Urban forestry. Recarbonizing global soils-A technical manual of recommended management practices: Volume 5-Forestry, wetlands, urban soils: Practices overview, 329.

Moran, M. S., Jackson, R. D., Slater, P. N., \& Teillet, P. M. (1992). Evaluation of simplified procedures for retrieval of land surface reflectance factors from satellite sensor 
output. Remote Sensing of Environment, 41(2-3), 169-184. https://doi.org/10.1016/0034-4257(92)90076-V

Mu, B., Mayer, A. L., He, R., \& Tian, G. (2016). Land use dynamics and policy implications in Central China: A case study of Zhengzhou. Cities, 58, 39-49. https://doi.org/10.1016/j.cities.2016.05.012

Rongali, G., Keshari, A. K., Gosain, A. K., \& Khosa, R. (2018). Split-window algorithm for retrieval of land surface temperature using Landsat 8 thermal infrared data. Journal of Geovisualization and Spatial Analysis, 2(2), 1-19. https://link.springer.com/article/10.1007/s41651-018-0021-y

Sekertekin, A., \& Bonafoni, S. (2020). Land surface temperature retrieval from Landsat 5, 7, and 8 over rural areas: assessment of different retrieval algorithms and emissivity models and toolbox implementation. Remote Sensing, 12(2), 294. https://doi.org/10.3390/rs12020294

Snyder, W. C., Wan, Z., Zhang, Y., \& Feng, Y.-Z. (1998). Classification-based emissivity for land surface temperature measurement from space. International Journal of Remote Sensing, 19(14), 2753-2774. https://doi.org/10.1016/j.rse.2004.02.003

Sobrino, J. A., Jiménez-Muñoz, J. C., \& Paolini, L. (2004). Land surface temperature retrieval from LANDSAT TM 5. Remote Sensing of environment, 90(4), 434-440.

Soltani, A., \& Sharifi, E. (2017). Daily variation of urban heat island effect and its correlations to urban greenery: A case study of Adelaide. Frontiers of Architectural Research, 6(4), 529-538. https://doi.org/10.1016/j.foar.2017.08.001

Sturman, A., \& Wanner, H. (2001). A Comparative Review of the Weather and Climate of the Southern Alps of New Zealand and the European Alps. Mountain Research and Development, 21(4), 359-369. http://www.jstor.org/stable/3674297

Tsou, J., Zhuang, J., Li, Y., \& Zhang, Y. (2017). Urban heat island assessment using the Landsat 8 data: a case study in Shenzhen and Hong Kong. Urban Science, 1(1), 10. https://www.mdpi.com/2413-8851/1/1/10

Ulivieri, C., \& Cannizzaro, G. (1985). Land surface temperature retrievals from satellite measurements. Acta Astronautica, 12(12), 977-985. https://doi.org/10.1016/0094$\underline{5765(85) 90026-8}$

Wang, F., Qin, Z., Song, C., Tu, L., Karnieli, A., \& Zhao, S. (2015). An improved monowindow algorithm for land surface temperature retrieval from Landsat 8 thermal infrared sensor data. Remote Sensing, 7(4), 4268-4289. https://doi.org/10.3390/rs70404268

Wang, W., Liu, K., Tang, R., \& Wang, S. (2019). Remote sensing image-based analysis of the urban heat island effect in Shenzhen, China. Physics and Chemistry of the Earth, Parts $A / B / C, 110,168-175$. https://doi.org/10.1016/j.pce.2019.01.002

Watkins, A. H., \& Thormodsgard, J. M. (1987). Higher resolution satellite remote sensing and the impact on image mapping. Acta Astronautica, 16, 221-232. https://doi.org/10.1016/0094-5765(87)90109-3

Yang, J., Wang, Y., Xiu, C., Xiao, X., Xia, J., \& Jin, C. (2020). Optimizing local climate zones to mitigate urban heat island effect in human settlements. Journal of Cleaner Production, 275, 123767. https://doi.org/10.1016/j.jclepro.2020.123767

Zheng, Q., Weng, Q., \& Wang, K. (2019). Developing a new cross-sensor calibration model for DMSP-OLS and Suomi-NPP VIIRS night-light imageries. ISPRS Journal of Photogrammetry and Remote Sensing, 153, 36-47. https://doi.org/10.1016/j.isprsjprs.2019.04.019 